\title{
TRAJECTORY-BASED ANALYSIS OF URBAN LAND-COVER CHANGE DETECTION
}

\author{
Y.H. Zhang ${ }^{\text {a, b, c }}$, H.P. Liu ${ }^{\text {a, b, c* }}$

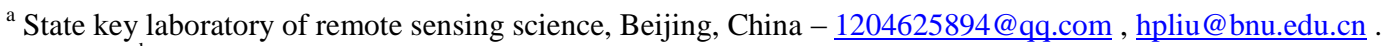 \\ ${ }^{\mathrm{b}}$ Beijing key laboratory of environmental remote sensing and digital city, Beijing, China \\ ${ }^{\mathbf{c}}$ School of Geography, Beijing Normal University, Beijing, China
}

KEY WORDS: change trajectory, similarity index, long time series, Landsat.

\begin{abstract}
:
China have occurred unprecedented urban growth over the last two decades. It is reported that the level of China's urbanization increased from $18 \%$ in 1978 to $41 \%$ in 2003 , and this figure may exceed $65 \%$ by 2050 . The change detection of long time serious remote sensing images is the effective way to acquire the data of urban land-cover change to understand the pattern of urbanization. In this paper, we proposed the similarity index (SI) and apply it in long time series urban land-cover change detection. First of all, we built possible change trajectories in four times based on the normalized difference vegetation index (NDVI) and modified normalized difference water index (MNDWI) that extracted from time series Landsat images. Secondly, we applied SI in similarity comparison between the observed change trajectory and the possible trajectories. Lastly, verifying the accuracy of the results. The overall accuracy in four periods is $85.7 \%$ and the overall accuracy of each two years is about $90 \%$ and kappa statistic is about 0.85 . The results show that this method is effective for time series land-cover change detection.
\end{abstract}

\section{INTRODUCTION}

Since the 20th century, with the continuous development of the city, more and more people keep pouring into cities to seek a variety of development opportunities. This has led to area of urban keep growing and area of forest and cultivated field keep reducing. Especially in China, Urban growth rates are unprecedented over the last two decades (Seto and Fragkias 2005) . According to the statistics, the level of China's urbanization increased from $18 \%$ in 1978 to $41 \%$ in 2003 , and this figure may exceed $65 \%$ by 2050 (Song and Ding 2009). In order to mitigate the effects of violent urban area expansion for the original land cover patterns, an up-to-date, quantitative, and accurate monitoring of urban dynamics is essential for proper urban planning and management.

In recent decades, with the development of earth observing system, remote sensing has been gradually applied to land use/cover change detection (Ridd and Liu 1998; Zhang and Seto 2011), and many change detection methods have been proposed (Lu et al. 2004) . Urban land use/cover change detection studies can be categorized as bi-temporal timescale studies (Ban and Yousif 2012; Du et al. 2012; He et al. 2011; Liu and Lathrop Jr 2002; Liu et al. 2004; Manonmani and Suganya 2010; Varshney 2013) , and multi-temporal timescale studies (DU et al. 2010; Kuang et al. 2016; Sexton et al. 2013; Shahraki et al. 2011; Xue et al. 2014a) . Long time series based urban change detection can obtain change process, but most previous studies have employed post-classification or bi-temporal change detection. These methods encounter error propagation and inconsistency. With the development of temporal resolution of remote sensing image, more and more land use/cover change detection studies have used time trajectory conception (Hais et al. 2009; Huang et al. 2010; Kennedy et al. 2007; Kennedy et al. 2010; Lehmann et al. 2013; Margono et al. 2012; Vogelmann et al. 2009; Zhu et al. 2012) in forest cover change detection. Martin used NDVI and tasseled cap index that extracted from multi-temporal landsat image to build forest change trajectory over times and analyzed the degree of the destruction of forests (Hais et al. 2009) . In this study, we would apply this conception in urban land-cover change detection and propose a long time series land cover change curve matching method which use similarity index.

According to the vegetation-impervious surface-soil (V-I-S) model proposed by Ridd (Ridd 1995), land cover in urban environments is a linear combination of three components: vegetation, impervious surface, and soil. We defined the land-cover types in an urban as urban land $(\mathrm{U})$, vegetation $(\mathrm{V})$, and waterbody (W). The objectives of this study are (1) to propose a similarity index that can get rid of threshold determination and (2) to apply this index in similarity comparison between the actual change types and the possible trajectories, and (3) to apply the method in monitoring urban expansion trajectories from Landsat time series.

\section{STUDY AREA AND DATA}

As a case study, we select the eastern region of Beijing. In recent decades, as the capital city of China, Beijing has developed rapidly in the economy and has growth rapidly in population, resulting in an increasing need for urban expansion and a great change of the landscape in the urban fringe area. The region selected with an extent of $1500 \mathrm{~km}^{2}$. This region contains not only the stable urban area but also the urban fringe area and is the possible region for the study.

A series of remote sensing images taken from the Landsat $5 \mathrm{TM}$ sensor and Landsat 8 OLI sensor covering the study area were selected to test the methodology. The series consisted of two TM images acquired in 2008 and 2011 and two OLI images acquired in 2013 and 2015. In order to minimize the effect of

\footnotetext{
* Corresponding author at: Beijing Normal University, No. 19, XinJieKouWai St., HaiDian District, Beijing 100875, PR China.
}

Tel.: +86 13701308210 .

E-mail address: hpliu@bnu.edu.cn (H. Liu) 
seasonal change, the acquisition dates of the chosen images mostly span from June to September.

To prepare the data for subsequent similarity matching of change trajectory, three procedures were carried out. First, all data were converted from the DN value to reflectance through calibration and choosing image acquired in 2011 as base image. Second, the base image were geometrically corrected and registered to reference image. The other Landsat images were then registered to base image with a root mean squared error of less than 0.5 pixels by image-to image registration. Third, taking radiometric normalization to all images based base image by pseudo invariant features method (Schott et al. 1988) to ensure that spectral values can be compared across time for any temporal change detection.

\section{METHODOLOGY}

\subsection{Characterizing possible trajectories}

In this paper, we categorized land cover in an urban area as vegetation $(\mathrm{V})$, urban $\operatorname{land}(\mathrm{U})$, waterbody $(\mathrm{W})$ and selected NDVI (Xue et al. 2014b; Zhu et al. 2012) and MNDWI (Xu 2006) to build change trajectory. We need statistical values of NDVI and MNDWI of urban land, vegetation, and waterbody. In order to obtain these statistics, we randomly sampled the study area and obtained samples of different land-cover types. According to these values of each land-cover type, we selected the average value of statistics as reference values to build possible temporal trajectories. Thirty-one kinds of possible change trajectories of land-cover types in four times were built. Conversion from other land-cover types to urban land is usually assumed to be irreversible (Liu and Zhou 2004), thus, once this change type happened, the temporal trajectory will be stable afterwards in NDVI and MNDWI changes.

\subsection{Trajectory similarity comparison based change detection}

We proposed the similarity index to compare observed temporal trajectory of each pixel with all the possible change trajectories. The possible change trajectory which has the maximum similarity with the observed change trajectory is the final change trajectory of each pixel. The similarity index (SI) was built by Euclidean distance index (ED) (Agrawal et al. 1993) and Jaccard index (Jac) (Egghe 2009; Jaccard 1912) that were calculated by temporal vectors. Let us denote the observed trajectory vector is $\mathrm{T}=\left(a_{1}, a_{2}, \ldots, a_{t}\right)$ and the possible change trajectory vector is $\mathrm{R}=\left(r_{1}, r_{2}, \ldots, r_{t}\right)$. Then, $\mathrm{ED}$ and Jac were calculated using the following formulas:

$$
\begin{aligned}
& \operatorname{ED}(\mathrm{T}, \mathrm{R})=\sqrt{\sum_{i=1}^{t}\left(a_{i}-r_{i}\right)^{2}} \\
& \operatorname{Jac}(T, R)=\frac{\sum_{i=1}^{t} a_{i} r_{i}}{\sum_{i=1}^{t} a_{i}^{2}+\sum_{i=1}^{t} r_{i}^{2}-\sum_{i=1}^{t} a_{i} r_{i}}
\end{aligned}
$$

Where, the ED (T,R) represents the Euclidean distance index of observed trajectory vector and possible change trajectory vector. The smaller ED value represents the smaller distance of observed trajectory and possible change trajectory. The Jac $(T, R)$ represents the Jaccard index of observed trajectory vector and possible change trajectory vector. The greater Jac value represents the greater similarity of the shape of observed trajectory and possible change trajectory. The $t$ represent the number of detected periods and we studied four periods urban land-cover change detection $(t=4)$ in this paper.

Considering the distance and shape of change trajectory curve together, we proposed similarity index (SI) which combined ED and Jac. SI was calculated using the following formulas:

$$
\begin{gathered}
\mathrm{SI}_{i}=\overline{\mathrm{Jac}}_{i}-\overline{\mathrm{ED}}_{i} \quad i=1,2 \ldots, n \\
\overline{\mathrm{Jac}}_{i}=\frac{J a c_{N D V I, i}+J a c_{M N D W I, i}}{2} \quad i=1,2 \ldots, n \\
\overline{\mathrm{ED}}_{i}=\frac{E D_{N D V I, i}+E D_{M N D W I, i}}{2} \quad i=1,2 \ldots, n
\end{gathered}
$$

Where, $\mathrm{SI}_{i}$ denotes the similarity index which calculated by observed trajectory vector and the $i$-th possible change trajectory vector. The $n$ represents the number of all possible change trajectories $(n=31)$. The $\overline{\mathrm{Jac}}_{\mathrm{i}}$ represents the means of Jac which was calculated by observed trajectory vector and the $i$-th possible change trajectory vector. The $\overline{\mathrm{ED}}_{i}$ represents the means of ED which was calculated by observed trajectory vector and the $i$-th possible change trajectory vector. The $\mathrm{Jac}_{\mathrm{NDVI}, \mathrm{i}}$ was calculated by observed NDVI change trajectory vector and the NDVI change trajectory vector of $i$-th possible change trajectory. The $\mathrm{Jac}_{\mathrm{MNDWI}} \mathrm{i}$ was calculated by observed MNDWI change trajectory vector and the MNDWI change trajectory vector of $i$-th possible change trajectory. The $\mathrm{ED}_{\mathrm{NDVI}, \mathrm{i}}$ was calculated by observed NDVI change trajectory vector and the NDVI change trajectory vector of $i$-th possible change trajectory. The $\mathrm{ED}_{\mathrm{MNDWI}, \mathrm{i}}$ was calculated by observed MNDWI change trajectory vector and the MNDWI change trajectory vector of $i$-th possible change trajectory.

Using the following formula 6 to determine final change trajectory of each pixel after obtain the similarity index of observed trajectory vector with all possible change trajectories.

$$
\mathrm{SI}_{m}=\max \left(\mathrm{SI}_{i}\right), \quad i=1,2, \ldots, 31
$$

Where $\mathrm{SI}_{\mathrm{m}}$ is the maximum similarity index of all similarity results of each pixel. The $m$ represents the possible change trajectory type corresponded to the maximum similarity and $\mathrm{m}$ also was the change detection result of each cell.

\subsection{Accuracy assessment}

In this article, we used the change-detection error matrix which is extended from the single-date classification error matrix (Story and Congalton 1986) to verify the accuracy. Because of it is difficult to obtain higher-resolution images or any other auxiliary dataset for such a long time series and the only available validation data set is the Landsat images themselves. Therefore, we obtained reference values by manual interpretation for each sample point. More than one thousand validation points were selected by the stratified random sampling method based on the area ratio of each change trajectory of results (Xue et al. 2014b) Based on the reference values, we plan to obtain the overall accuracy of change detection result in four periods and the change-detection error matrix every two years.

\section{RESULTS}

Figure 1 shows the change detection results from 2008 to 2015 From Figure 1we can see that most of study area is occupied 
by stable urban (interpreted as a bright red area) and stable vegetation (interpreted as a dark green area). Stable urban occupy $24 \%$ study area and stable vegetation occupy $50 \%$ study area. The area interpreted as blue is stable waterbody. The change area is mostly occupied by the change type of vegetation to urban land (interpreted as a pink area). This area occupied 13\% study area.

Based on reference points' values, the overall accuracy of change detection in four periods is $85.7 \%$ and the overall accuracy of each two years is about $90 \%$ and kappa statistic is about 0.85 . From the user accuracy and producer accuracy we can see that the stable area have a small commission error. The type of vegetation change to waterbody (VW) has a relative high commission error. This might was caused by the registration error or irrigated vegetation that has a high MNDWI value and low NDVI value. Therefore, some stable vegetation area was observed as vegetation change to waterbody. The type of waterbody change to urban land (WU) also has a high commission error. This was might caused by the shadow of building that has the same characters as waterbody. Therefore, some stable urban or stable waterbody was observed as waterbody change to urban. This also the reason of that stable waterbody has a high omission. This can be avoided by orthorectification. Due to these types that have a high commission error occupy small percent of study area, therefore it has little effect to the results.

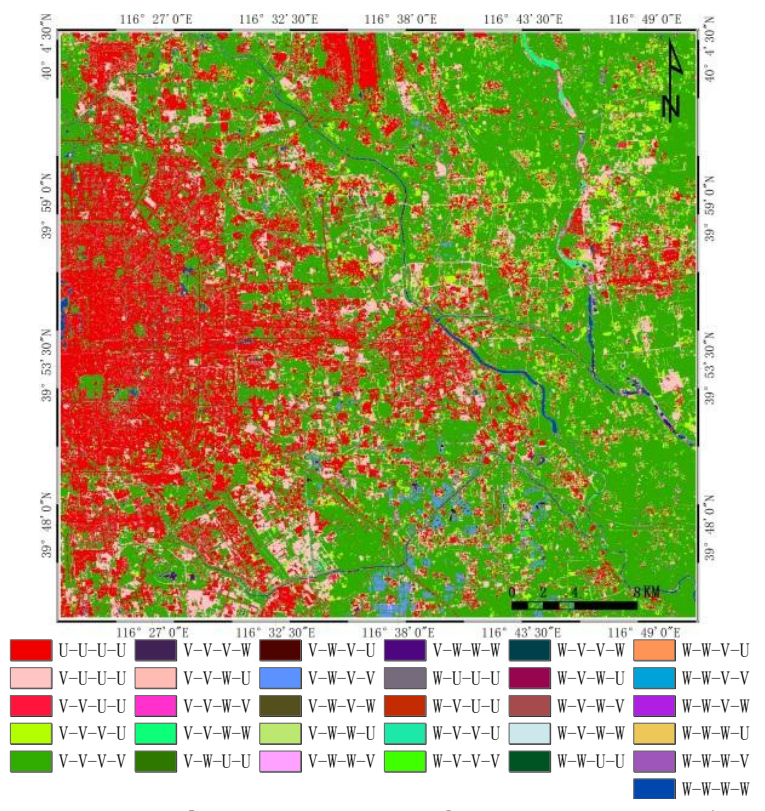

Figure 1 change trajectory from 2008 to 2015

\section{CONCLUSIONS}

In this article, we proposed a similarity comparison method to monitoring the urban change in four periods. The data and study area is Landsat images and eastern region of Beijing. Change indicator trajectories (NDVI and MNDWI) were established to reveal land-cover change trajectories. Based on the understanding that land-cover change will lead to the change of indicator trajectory, we built all possible change trajectories in four periods by the indicator composition. Then we used the similarity index (SI) to compare observed trajectory of each pixel with all possible trajectories. The possible change trajectory correspond to maximum similarity index is final result of the pixel. This method avoids threshold determination that might affect the accuracy of results and reveal change process of urban land-cover. We can not only apply this method to four periods, but also apply it to more or less than four periods. The overall accuracy in four periods is $85.7 \%$ and the overall accuracy of each two years is about $90 \%$ and kappa statistic is about 0.85 . Even though exist some commission error and omission error, this error occupy small percent of study area and have little effect to the accuracy of results. Thus, this method is effectively to apply in time series urban land-cover change detection.

However, this study also has limitation. The possible trajectories are increasing with the increase of time series. It is difficult to build possible trajectories in more than four periods, even it can be done by spent much time.

\section{REFERENCES}

Ban, Y., \& Yousif, O. (2012). Multitemporal spaceborne SAR data for urban change detection in China. Selected Topics in Applied Earth Observations and Remote Sensing, IEEE Journal of, 5, 1087-1094

DU, P., LI, X., Cao, W., Luo, Y., \& ZHANG, H. (2010). Monitoring urban land cover and vegetation change by multi-temporal remote sensing information. Mining Science and Technology (China), 20, 922-932

Du, P., Liu, S., Gamba, P., Tan, K., \& Xia, J. (2012). Fusion of difference images for change detection over urban areas. Selected Topics in Applied Earth Observations and Remote Sensing, IEEE Journal of, 5, 1076-1086

Hais, M., Jonášová, M., Langhammer, J., \& Kučera, T. (2009). Comparison of two types of forest disturbance using multitemporal Landsat TM/ETM+ imagery and field vegetation data. Remote Sensing Of Environment, 113, 835-845

He, C., Wei, A., Shi, P., Zhang, Q., \& Zhao, Y. (2011). Detecting land-use/land-cover change in rural-urban fringe areas using extended change-vector analysis. International Journal of Applied Earth Observation and Geoinformation, 13, 572-585 Huang, C., Goward, S.N., Masek, J.G., Thomas, N., Zhu, Z., \& Vogelmann, J.E. (2010). An automated approach for reconstructing recent forest disturbance history using dense Landsat time series stacks. Remote Sensing Of Environment, 114, 183-198

Kennedy, R.E., Cohen, W.B., \& Schroeder, T.A. (2007). Trajectory-based change detection for automated characterization of forest disturbance dynamics. Remote Sensing Of Environment, 110, 370-386

Kennedy, R.E., Yang, Z., \& Cohen, W.B. (2010). Detecting trends in forest disturbance and recovery using yearly Landsat time series: 1. LandTrendr-Temporal segmentation algorithms. Remote Sensing Of Environment, 114, 2897-2910

Kuang, W., Liu, J., Dong, J., Chi, W., \& Zhang, C. (2016). The rapid and massive urban and industrial land expansions in China between 1990 and 2010: A CLUD-based analysis of their trajectories, patterns, and drivers. Landscape And Urban Planning, 145, 21-33

Lehmann, E.A., Wallace, J.F., Caccetta, P.A., Furby, S.L., \&

Zdunic, K. (2013). Forest cover trends from time series Landsat data for the Australian continent. International Journal of Applied Earth Observation and Geoinformation, 21, 453-462

Liu, H., \& Zhou, Q. (2004). Accuracy analysis of remote sensing change detection by rule-based rationality evaluation with post-classification comparison. International Journal Of Remote Sensing, 25, 1037-1050

Liu, X., \& Lathrop Jr, R.G. (2002). Urban change detection based on an artificial neural network. International Journal of Remote Sensing, 23, 2513-2518

Liu, Y., Nishiyama, S., \& Yano, T. (2004). Analysis of four change detection algorithms in bi-temporal space with a case study. International Journal Of Remote Sensing, 25, 2121-2139 
Lu, D., Mausel, P., Brondizio, E., \& Moran, E. (2004). Change detection techniques. International Journal Of Remote Sensing 25, 2365-2401

Manonmani, R., \& Suganya, G.M.D. (2010). Remote sensing and GIS application in change detection study in urban zone using multi temporal satellite. International journal of Geomatics and Geosciences, 1, 60-65

Margono, B.A., Turubanova, S., Zhuravleva, I., Potapov, P., Tyukavina, A., Baccini, A., Goetz, S., \& Hansen, M.C. (2012). Mapping and monitoring deforestation and forest degradation in Sumatra (Indonesia) using Landsat time series data sets from 1990 to 2010. Environmental Research Letters, 7, 34010 Ridd, M.K. (1995). Exploring a VIS (vegetation-impervious surface-soil) model for urban ecosystem analysis through remote sensing: comparative anatomy for cities $\dagger$. International Journal Of Remote Sensing, 16, 2165-2185

Ridd, M.K., \& Liu, J. (1998). A comparison of four algorithms for change detection in an urban environment. Remote Sensing Of Environment, 63, 95-100

Schott, J.R., Salvaggio, C., \& Volchok, W.J. (1988). Radiometric scene normalization using pseudoinvariant features. Remote Sensing Of Environment, 26, 1-16

Seto, K.C., \& Fragkias, M. (2005). Quantifying spatiotemporal patterns of urban land-use change in four cities of China with time series landscape metrics. Landscape Ecology, 20, 871-888 Sexton, J.O., Song, X., Huang, C., Channan, S., Baker, M.E., \& Townshend, J.R. (2013). Urban growth of the Washington, D.C.-Baltimore, MD metropolitan region from 1984 to 2010 by annual, Landsat-based estimates of impervious cover, 129 , 42-53

Shahraki, S.Z., Sauri, D., Serra, P., Modugno, S., Seifolddini, F., \& Pourahmad, A. (2011). Urban sprawl pattern and land-use change detection in Yazd, Iran. Habitat International, 35, 521-528

Song, Y., \& Ding, C. (2009). Smart urban growth for China: Lincoln Institute of Land Policy

Story, M., \& Congalton, R.G. (1986). Accuracy assessment-A userl's perspective. Photogrammetric Engineering And Remote Sensing, 52, 397-399

Varshney, A. (2013). Improved NDBI differencing algorithm for built-up regions change detection from remote-sensing data: an automated approach. Remote Sensing Letters, 4, 504-512 Vogelmann, J.E., Tolk, B., \& Zhu, Z. (2009). Monitoring forest changes in the southwestern United States using multitemporal Landsat data. Remote Sensing Of Environment, 113, 1739-1748 $\mathrm{Xu}, \mathrm{H}$. (2006). Modification of normalised difference water index (NDWI) to enhance open water features in remotely sensed imagery. International Journal Of Remote Sensing, 27, 3025-3033

Xue, X., Liu, H., Mu, X., \& Liu, J. (2014a). Trajectory-based detection of urban expansion using Landsat time series. International Journal Of Remote Sensing, 35

Xue, X., Liu, H., Mu, X., \& Liu, J. (2014b). Trajectory-based detection of urban expansion using Landsat time series. International Journal Of Remote Sensing, 35

Zhang, Q., \& Seto, K.C. (2011). Mapping urbanization dynamics at regional and global scales using multi-temporal DMSP/OLS nighttime light data. Remote Sensing Of Environment, 115, 2320-2329

Zhu, Z., Woodcock, C.E., \& Olofsson, P. (2012). Continuous monitoring of forest disturbance using all available Landsat imagery. Remote Sensing Of Environment, 122, 75-91 